\title{
Impact of the COVID-19 Event on the Characteristics of Atmospheric Single Particle in the Northern China
}

\author{
Zheng $\mathrm{Li}^{1}$, Jingjing Meng ${ }^{1 *}$, Ling Zhou ${ }^{2}$, Ruiwen Zhou ${ }^{1}$, Mengxuan Fu ${ }^{1}$, Yachen Wang ${ }^{1}$, \\ Yanan Yi ${ }^{1}$, Aijing Song ${ }^{1}$, Qingchun Guo ${ }^{1}$, Zhanfang Hou ${ }^{1}$, Li Yan ${ }^{3}$ \\ ${ }^{1}$ School of Environment and Planning, Liaocheng University, Liaocheng 252000, China \\ ${ }^{2}$ College of Resources and Environment, Xingtai University, Xingtai 054000, China \\ ${ }^{3}$ Chinese Academy for Environmental Planning, Beijing 100012, China
}

\begin{abstract}
The COVID-19 event triggered global attention which broke out at the end of 2019. To investigate the impact of the COVID-19 pandemic prevention and control actions on the chemical composition, size distribution, and mixing state of individual particles, real-time individual particles in the urban atmosphere of the Northern China were analyzed using single particle aerosol mass spectrometry (SPAMS) during January 16 to February 4, 2020. The results showed that the concentrations of $\mathrm{PM}_{2.5}, \mathrm{NO}_{\mathrm{x}}$, and $\mathrm{CO}$ were lower during DP (during the pandemic) than those during $\mathrm{BP}$ (before the pandemic), while $\mathrm{O}_{3}$ concentration increased by about $40.9 \%$ during DP due to a lower concentration of $\mathrm{NO}_{2}$ restraining the decomposition of $\mathrm{O}_{3}$ via the reaction of $\mathrm{NO}$ with $\mathrm{O}_{3}$. The number count of carbonaceous particles during DP decreased by $20.2 \%$ compared to that during BP due to the sharp reduction of factory production and vehicular transportation during DP. Dust particles during DP exhibited weaker ${ }^{23} \mathrm{Na}^{+},{ }^{56} \mathrm{Fe}^{+}$, and ${ }^{79} \mathrm{PO}_{3}{ }^{-}$signals than those during BP, suggesting that dust particles during DP were mostly derived from mineral dust rather than industrial sources. The total particles during DP peaked at a larger size than those during BP, due to the higher fraction of secondary inorganic ions through the enhanced heterogeneous aqueous oxidation. The unscaled size distribution of total particles peaked at $0.50 \mu \mathrm{m}$ during BP and at $0.66-0.70 \mu \mathrm{m}$ during DP, suggesting that particles remained for a long time in the atmosphere and went through a strong aging process during DP. The single particles during DP were more aged than those during BP, owing to the stronger atmospheric oxidizing capacity during DP.
\end{abstract}

Keywords: Size distribution; Mixing state; COVID-19 pandemic; the North China Plain (NCP); Single particle aerosol mass spectrometry (SPAMS).

\section{INTRODUCTION}

A novel coronavirus broke out in December 2019 and quickly spread across the world. This pandemic is receiving increasing attention internationally (Tian et al., 2020; Wang et al., 2020). The World Health Organization regarded the disease as a worldwide pandemic and named "COVID-19" on March 11, 2020 (Jin et al., 2020). As of July $10^{\text {th }} 2020$, there have been more than 12 million confirmed cases of COVID19, including 549247 deaths (https://covid19.who.int/). Prevention and control actions, including the city lockdown, suspending factory production, and imposing traffic restrictions, have been implemented in many countries to prevent the spread of epidemic. Therefore, the air quality in many areas has improved significantly due to the sharp reduction of pollution

\footnotetext{
* Corresponding author.

E-mail address: mengjingjing@lcu.edu.cn
}

sources such as vehicle exhausts, fossil fuel combustion, and industrial activities. The Finish Centre for Research on Energy and Clean Air reported that the concentration of $\mathrm{CO}_{2}$ during the pandemic was around $25 \%$ less than that before the epidemic due to the measures such as travel restrictions and factory closures (https://www.carbonbrief.org). Tobías et al. (2020) have reported the air quality has been markedly improved during two weeks of closure of Barcelona city, Spain. The reduction in the concentrations of $\mathrm{PM}_{10}, \mathrm{PM}_{2.5}$, $\mathrm{SO}_{2}, \mathrm{NO}_{2}$ and $\mathrm{CO}$ were detected during February 2020 in central and near central China compared to January February 2017-2019, while $\mathrm{O}_{3}$ concentration did not present significant downtrend and even slightly increased by $3.6 \%$ (Xu et al., 2020a, b). Moreover, a dramatic reduction in the concentration of major atmospheric pollutants across China was observed during the pandemic (Wang, et al., 2020).

The atmospheric aerosols have attracted much public attention because of their significant impact on air quality, visibility, human health, and global climate change (An et al., 2019; Li et al., 2019; Meng et al., 2020). The effect of 
atmospheric aerosols on radiative forcing and cloud condensation nuclei $(\mathrm{CCN})$ is closely associated with their chemical and physical properties (Wang et al., 2016a; Hu et $a l ., 2018)$. To investigate the evolution process and formation mechanism of single particles, it is significantly crucial to understand the chemical compositions and physicochemical properties of single particles with high time resolution. Single particle aerosol mass spectrometer (SPAMS) is of advantages for real-time and continuous monitoring on-line and it is increasingly used to study the chemical composition, size distribution, and mixing state of both ambient and laboratory generated aerosols, further deepening our understanding of the sources, aging processes, and physicochemical properties of atmospheric aerosols. SPAMS has been extensively used to investigate the characteristics of individual particles in the urban atmosphere of Guangzhou (Zhang et al., 2015; Cheng et al., 2017; Lu et al., 2019), Beijing (Ma et al., 2016a; Ma et al., 2016b) and Shanghai (Zhai et al., 2015). However, most of the studies were conducted in megacities and the chemical composition, size distribution, and mixing state of single particles by SPAMS in the small and medium-size inland cities have not been performed, especially in the North China Plain (NCP) (Yan et al., 2018). To the best of our knowledge, the impact of COVID-19 on the characteristics of single particles have not been reported. In addition, the reduced anthropogenic impact on the atmospheric aerosol during the pandemic can help us better understand the influence of human activities on the physicochemical properties and mixing states of aerosols.

In recent decades, the North China Plain has been facing extremely severe and persistent haze pollution due to rapid urbanization and industrialization, especially in the autumn and winter seasons. Liaocheng City, located in the center of the North China Plain, is ranked as the top $30^{\text {th }}$ most polluted city among 366 Chinese cities with the highest daily concentration of $\mathrm{PM}_{2.5}$ (https://www.aqistudy.cn/?tdsourcetag=Spcqq_aio $\mathrm{msg}$ ). In addition, Liaocheng was listed as a Jing-Jin-Ji air pollution transmission channel city, providing that the regional transport of atmospheric pollutants from Liaocheng was identified to contribute significantly to air pollution in this region. A few studies have been conducted to investigate the molecular compositions and sources of organic aerosols and the aqueous phase formation of dicarboxylic acids and related compounds during the haze event in Liaocheng (Liu et al., 2019; Meng et al., 2020). However, most of these studies were conducted using off-line analysis, which provided limited information on the molecular characteristics, size distribution, and mixing state of single particles, particularly during the COVID-19 pandemic. In this study, we analyze the real-time individual particles in Liaocheng using SPAMS during January 16 to February 4, 2020 with focus on the impact of the COVID-19 pandemic on the chemical composition, size distribution, and mixing state of individual particles.

\section{METHODS}

\section{Aerosol Sampling}

As one of the " $2+26$ " air pollution transmission channel cities of China, Liaocheng is located in the southwestern part of Shandong Province in the North China Plain (NCP). The single particle aerosol mass spectrometer (SPAMS, 0515R Model, Hexin Analytical Instrument Co., Ltd., China) was placed on the rooftop of a six-story building $\left(36.43^{\circ} \mathrm{N}\right.$, $116.01^{\circ} \mathrm{E}$ ) in the Liaocheng University, which is located in the southeast of Liaocheng ( $25 \mathrm{~m}$ above ground). The sampling site is surrounded by roads and residential area with no tall buildings and major pollution sources nearby. Ambient particles were introduced from the sampling inlet, which was set up about $28 \mathrm{~m}$ above ground to the SPAMS through a Tygon tube of $\sim 3 \mathrm{~m}$ long. Ambient aerosols were collected hourly by SPAMS at a flow rate of $75 \mathrm{~mL} \mathrm{~min}^{-1}$. In this study, the observation period was from 0:00 January 16 to 24:00 February 4, 2020. To investigate the impact of the COVID-19 pandemic on the characteristics of ambient single particles, the whole sampling period was divided into "before the pandemic" (BP, from 0:00 January 16 to 23:00 January 23, 2020) and "during the pandemic" (DP, from 0:00 January 23 to 24:00 February 4, 2020). Meteorological parameters (e.g., relative humidity, temperature, visibility, and solar radiation) and the concentration of $\mathrm{SO}_{2}, \mathrm{NO}_{\mathrm{x}}$, and $\mathrm{O}_{3}$ were retrieved from the website of Environmental Protection Bureau of Liaocheng (http://www.lchbj.gov.cn).

\section{SPAMS and Data Analysis}

SPAMS is designed to determine the real-time size distribution and chemical composition of ambient single particles. A detailed description has been published in previous studies (Li et al., 2011). Ambient aerosols were sampled through a $100 \mu \mathrm{m}$ metal orifice into instrument at a flow rate of $75 \mathrm{~mL} \mathrm{~min}{ }^{-1}$. Particles has been accelerated to specific velocities and sized by two continuous diode Nd:YAG (neodymium-doped yttrium aluminum garnet) laser beams (532 nm). Finally, the sized particles were desorption/ ionization by $266 \mathrm{~nm} \mathrm{Nd}$ :YAG pulsed laser beams. The ions were then analyzed by a bipolar time-of-flight mass spectrometer. The SPAMS can analyze the size range from 0.1 to $2.0 \mu \mathrm{m}$ and determine the chemical composition and mass spectra. A dryer was installed in front of the sampling tube to avoid the influence of the varying relative humidity (RH). To reduce the residence time of particle in the tube, an additional pump was connected to the sampling tube $\left(3 \mathrm{~L} \mathrm{~min}^{-1}\right)$.

The particle data was analyzed using Matlab 2014b (Math Work Inc., Natick, MA, USA). Particles were classified using adaptive resonance theory neural network algorithm (ART-2a). In this study, the single particles were analyzed by ART-2a with learning rate of 0.05 , a vigilance factor of 0.7 , and a maximum of 20 iterations. ART-2a classification was based on the presence and intensity of ion peaks of individual particle spectra. In this study, a total of 986 clusters representing $\sim 95 \%$ of the collected particles were clustered and eight major types were manually grouped based on distinct mass spectra and size distribution.

\section{RESULTS AND DISCUSSION}

\section{Comparison of Gaseous Pollutants and Meteorological Conditions between BP and DP}

Temporal variations in the concentration of gaseous 
pollutants and meteorological factors between BP and DP are summarized in Table 1 and compared in Fig. 1. The average concentration of $\mathrm{PM}_{2.5}$ was $119.6 \pm 53.9 \mu \mathrm{g} \mathrm{m}^{-3}$ in the whole sampling campaign, which was lower than that in the same period of $2019\left(130.0 \pm 70.0 \mu \mathrm{g} \mathrm{m}^{-3}\right.$ ) (Liu et al., 2019), indicating that the air quality of Liaocheng has been improved greatly in the recent two years due to great efforts made by the municipal government of Liaocheng (Meng et al., 2020). The concentrations of $\mathrm{PM}_{2.5}$ decreased dramatically from BP $\left(142.4 \pm 48.9 \mu \mathrm{g} \mathrm{m}^{-3}\right)$ to DP $\left(96.7 \pm 48.8 \mu \mathrm{g} \mathrm{m}^{-3}\right)$. There may be two reasons for such a significant reduction: (1) Most factories and companies were closed in the Chinese lunar New Year holidays, resulting in greatly reduction in the pollutant emissions from industrial production and other sources; (2) The strict pandemic prevention and control actions were implemented by the government, leading to the decrement in emissions from industrial exhaust and automobile exhaust. The concentration of $\mathrm{SO}_{2}$ exhibited a similar level between $\mathrm{BP}\left(12.9 \pm 7.8 \mu \mathrm{g} \mathrm{m}^{-3}\right)$ and DP $\left(13.9 \pm 7.5 \mu \mathrm{g} \mathrm{m}^{-3}\right)$, due to the uninterrupted emissions of $\mathrm{SO}_{2}$ from petrochemical facilities and power plants (Le et al., 2020). However, $\mathrm{NO}_{\mathrm{x}}$ concentration decreased sharply from $40.0 \pm 18.3 \mu \mathrm{g} \mathrm{m}^{-3}$ during BP to $19.5 \pm 6.3 \mu \mathrm{g} \mathrm{m}^{-3}$ during DP, mainly because the on-road vehicle numbers drastically reduced when strict pandemic prevention and control actions were taken during DP. Similar to $\mathrm{PM}_{2.5}$ and $\mathrm{NO}_{\mathrm{x}}, \mathrm{CO}$ concentration displayed a decreasing trend from BP $\left(1.5 \pm 0.5 \mathrm{mg} \mathrm{m}^{-3}\right)$ to DP $(1.1 \pm$ $\left.0.4 \mathrm{mg} \mathrm{m}^{-3}\right)$, indicating that fossil fuel combustion was reduced significantly during DP. $\mathrm{O}_{3}$ is mostly originated from the photochemical reaction of $\mathrm{CO}, \mathrm{NO}_{\mathrm{x}}$, and VOCs (volatile organic compounds) in the atmosphere. Thus, it was used as an indicator of atmospheric oxidation capacity. As shown in
Table 1 and Fig. 1, the average concentration $(68.5 \pm 21.6$ $\mu \mathrm{g} \mathrm{m}^{-3}$ ) of $\mathrm{O}_{3}$ increased by about $40.9 \%$ during DP compared to that $\left(40.5 \pm 24.2 \mu \mathrm{g} \mathrm{m}^{-3}\right)$ during $\mathrm{BP}$, mainly because a lower concentration of $\mathrm{NO}_{2}$ restrained the decomposition of $\mathrm{O}_{3}$ via the reaction of $\mathrm{NO}$ with $\mathrm{O}_{3}$ (Xu et al., 2020a, b), resulting in $\mathrm{O}_{3}$ level increased during DP. Moreover, the higher concentration of $\mathrm{O}_{3}$ suggested that the atmospheric oxidizing capacity was stronger during DP than during BP.

Temperature during the sampling period exhibited an increasing trend, with averages of $0.8 \pm 2.6^{\circ} \mathrm{C}$ and $1.8 \pm 3.5^{\circ} \mathrm{C}$ during BP and DP, respectively. Solar radiation $(73.2 \pm 1$ 29.1 wat $\mathrm{m}^{-2}$ ) was much stronger during DP compared with that $\left(100.8 \pm 165.3\right.$ wat $\left.^{-2}\right)$ during BP. Visibility was 1.9 times higher during DP than that during BP, largely due to the reduction in $\mathrm{PM}_{2.5}$ mass concentration during DP. RH was also higher $(77.69 \pm 16.85 \%)$ during DP than that $(65.43 \pm$ $18.11 \%$ ) during BP. Both ratios of sulfate to $\mathrm{SO}_{2}$ and nitrate to $\mathrm{NO}_{\mathrm{x}}$ were regarded as an indicator of aerosol aging (Jiang et al., 2019). As shown in Table 1, these two ratios were higher during DP than those during BP, suggesting that the atmospheric aerosols were more aged during DP due to the higher temperature, stronger solar radiation, and higher $\mathrm{O}_{3}$ concentration during DP, which is in favor of the formation of sulfate and nitrate.

\section{Differences in the Characteristic of Single Particle between $B P$ and $D P$}

In this study, a total of 1373953 particles and 1361662 particles were obtained with both positive and negative mass spectrum during BP and DP, respectively. ART-2a was employed to classify individual particles into eight groups according to the major ion peak of each particle: elemental

Table 1. Concentrations of $\mathrm{PM}_{2.5}$ and meteorological factors, and count of each particle types during BP and DP.

\begin{tabular}{llll}
\hline & Whole period & Before the pandemic & During the pandemic \\
\hline $\mathrm{PM}_{2.5}\left(\mu \mathrm{g} \mathrm{m}^{-3}\right)$ & $119.6 \pm 53.9$ & $142.4 \pm 48.9$ & $96.7 \pm 48.8$ \\
\hline Meteorological parameters & & & \\
Temperature $\left({ }^{\circ} \mathrm{C}\right)$ & $1.3 \pm 3.2$ & $0.8 \pm 2.6$ & $1.8 \pm 3.5$ \\
Relative humidity $(\%)$ & $71.6 \pm 18.5$ & $2.0 \pm 2.2$ & $65.43 \pm 18.11$ \\
Visibility $(\mathrm{km})$ & $2.9 \pm 2.8$ & $73.2 \pm 129.1$ & $3.8 \pm 2.9$ \\
Solar Radiation & $87.0 \pm 139.5$ & & $100.8 \pm 165.3$ \\
$\mathrm{Gas}_{\text {pollutants }}$ & & $40.5 \pm 24.2$ & $68.5 \pm 21.6$ \\
$\mathrm{O}_{3}\left(\mu \mathrm{g} \mathrm{m}^{-3}\right)$ & $54.5 \pm 26.8$ & $12.9 \pm 7.8$ & $13.9 \pm 7.5$ \\
$\mathrm{SO}_{2}\left(\mu \mathrm{g} \mathrm{m}^{-3}\right)$ & $13.4 \pm 7.6$ & $40.0 \pm 18.3$ & $19.5 \pm 6.3$ \\
$\mathrm{NO}_{2}\left(\mu \mathrm{g} \mathrm{m}^{-3}\right)$ & $29.8 \pm 17.1$ & $1.5 \pm 0.5$ & $1.1 \pm 0.4$ \\
$\mathrm{CO}\left(\mathrm{mg} \mathrm{m}^{-3}\right)$ & $1.3 \pm 0.5$ & & 367486 \\
$\mathrm{Sample} \mathrm{classification} \mathrm{(number} \mathrm{count)}$ & & 455718 & 89222 \\
EC & 828204 & 101774 & 235977 \\
ECOC & 190996 & 310217 & 51604 \\
OC & 546194 & 34069 & 379523 \\
Dust & 85673 & 266228 & 155962 \\
$\mathrm{~K}-$ rich & 645751 & 141964 & 52446 \\
levoglucosan & 297926 & 50588 & 1361662 \\
$\mathrm{HM}$ & 103034 & 1373953 & $443.9 \pm 196.3$ \\
Total & 2735615 & $275.7 \pm 200.5$ & $155.0 \pm 84.6$ \\
Ratio of major species & & $146.6 \pm 47.6$ & \\
sulfate/ $\mathrm{SO}_{2}$ & $360.9 \pm 215.2$ & & \\
nitrate/ $\mathrm{NO}_{2}$ & $150.7 \pm 68.3$ & &
\end{tabular}




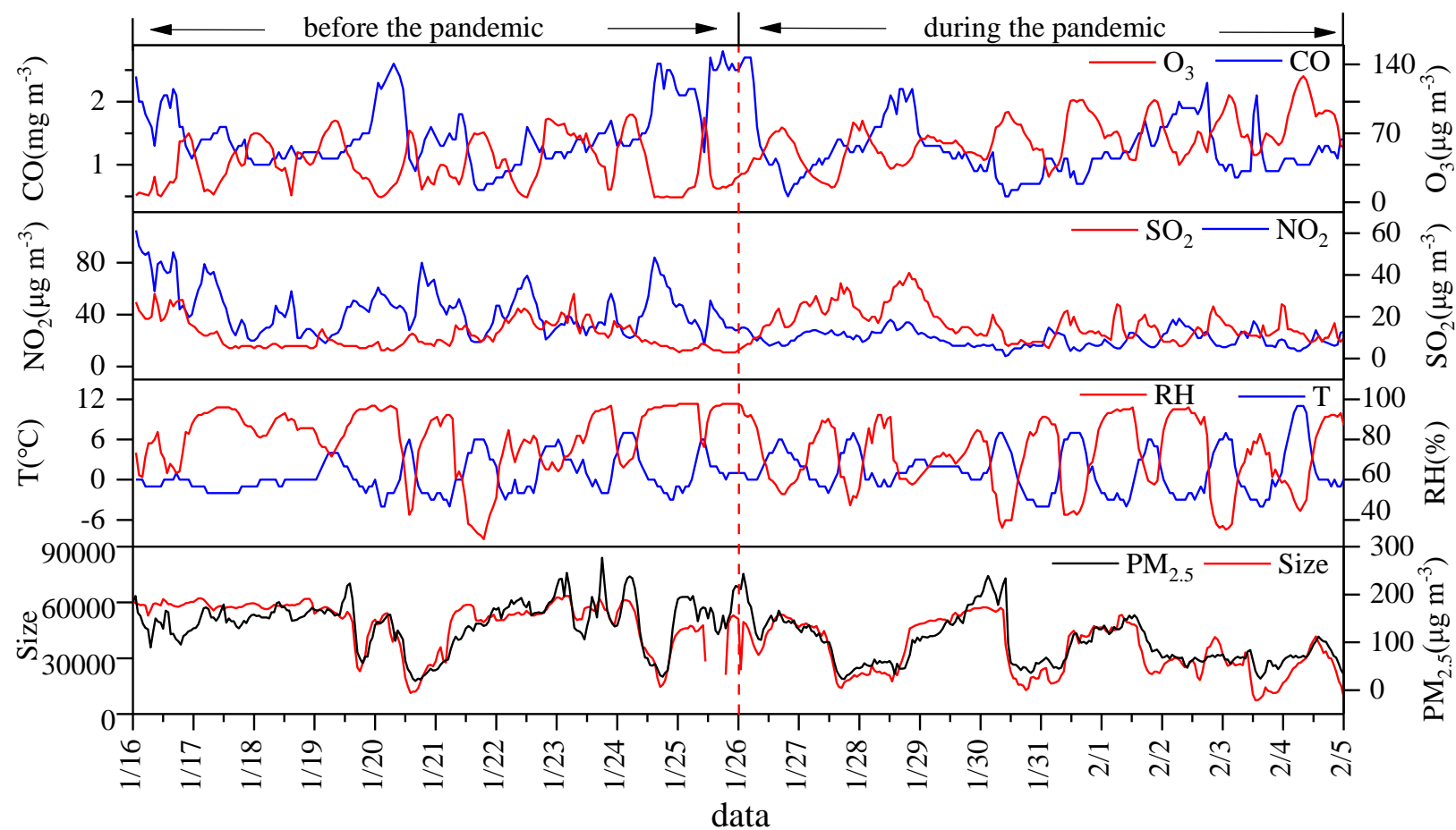

Fig. 1. Comparison of gaseous pollutants and meteorological conditions during BP and DP.

carbon (EC), EC, and OC combined particles (ECOC), organic carbon (OC), dust particles (Dust), K-rich, levoglucosan, HM (heavy metals) and Other. Representative mass spectra of the eight types of particles during BP and DP were exhibited in Fig. 2.

\section{Carbonaceous Species}

The mass spectra of EC, ECOC, and OC did not show significant difference during BP and DP. As shown in Fig. 2, EC, ECOC, and OC were dominated by $\mathrm{C}_{\mathrm{n}}{ }^{+}(n=1,2, \ldots 6)$ peaks in the positive mass spectrum in both BP and DP. There was a significant signal intensity of secondary inorganic ions such as ${ }^{46} \mathrm{NO}_{2}{ }^{-},{ }^{62} \mathrm{NO}_{3}{ }^{-}$, and ${ }^{97} \mathrm{HSO}_{4}^{-}$in the negative mass spectrum of $\mathrm{EC}, \mathrm{ECOC}$, and $\mathrm{OC}$ during the whole observation period, suggesting that carbonaceous species experienced aging process in the atmosphere of Liaocheng. The signal intensity of both $\mathrm{C}_{\mathrm{n}}{ }^{+}$and $\mathrm{C}_{\mathrm{n}} \mathrm{H}_{\mathrm{m}}{ }^{+}(n=$ $1-6, m=1-3$ ) in the positive mass spectrum during BP were stronger than those during DP, but a weaker signal of ${ }^{97} \mathrm{HSO}_{4}^{-}$was detected during $\mathrm{BP}$ than that during DP. Previous studies have reported that EC and OC were emitted from motor vehicle exhausts, fossil fuel combustion and biomass burning (Liu and Shao, 2007; Sun et al., 2013; Li et al., 2014; Jain et al., 2018). Levoglucosan in the atmosphere was stable enough and thus it was used as a reliable indicator of biomass burning (Simoneit et al., 2004; Mochida et al., 2010). As shown in Fig. 3(a), there were no correlations between EC and levoglucosan in both $\mathrm{BP}$ and DP, indicating that the effect of biomass burning on EC was minor. OC was robustly correlated with levoglucosan $\left(R^{2}=0.5\right)$ during $\mathrm{BP}$, but no correlation was observed during DP. These results suggest that biomass burning was an important contributor to $\mathrm{OC}$ only during $\mathrm{BP}$, but EC during BP and DP as well as
OC during DP were largely derived from vehicle exhausts and fossil fuel combustion. Moreover, the number counts of carbonaceous particles during DP (867709) decreased by $20.2 \%$ compared to that (692685) during BP, due to the sharp reduction of factory production and vehicular transport during DP.

\section{Dust}

In contrast to the variations of carbonaceous particles, the average number fraction of dust particles increased from 34069 during BP to 51604 during DP, largely attributed to the enhanced emission of local dust particles during DP. The positive ion mass spectra of dust particles were characterized by the high intensity of crustal element including ${ }^{23} \mathrm{Na}^{+}$, ${ }^{24} \mathrm{Mg}^{+},{ }^{27} \mathrm{Al}^{+},{ }^{40} \mathrm{Ca}^{+}$, and ${ }^{56} \mathrm{Fe}^{+}$. In addition, the negative ion mass spectrum was dominated by ${ }^{46} \mathrm{NO}_{2}^{-},{ }^{62} \mathrm{NO}_{3}^{-}$, and ${ }^{97} \mathrm{HSO}_{4}^{-}$. Previous studies have demonstrated that particles are identified to be aged when the high signal intensity of secondary ions, including ammonium, nitrate, and sulfate, are obtained in the negative mass spectra (Zhang et al., 2015). Generally, the more aged particles are observed with the more abundant signals of nitrate than sulfate obtained in the mass spectra. As shown in Fig. 2, the relatively high signal intensities of nitrate $\left({ }^{46} \mathrm{NO}_{2}{ }^{-},{ }^{62} \mathrm{NO}_{3}{ }^{-}\right)$and the low signal intensity of sulfate $\left({ }^{97} \mathrm{HSO}_{4}^{-}\right)$in dust particles were obtained during the whole observation period, suggesting that the dust particles has been suspended for a long time in the atmosphere and experienced a significant ageing process. The dust particles during DP showed a more significant peak of secondary inorganic ions compared to that during BP, indicating that the particles during DP were more aged, which was consistent with our above discussions. ${ }^{23} \mathrm{Na}^{+}$, ${ }^{56} \mathrm{Fe}^{+}$, and ${ }^{79} \mathrm{PO}_{3}^{-}$are mainly emitted from industrial sources 

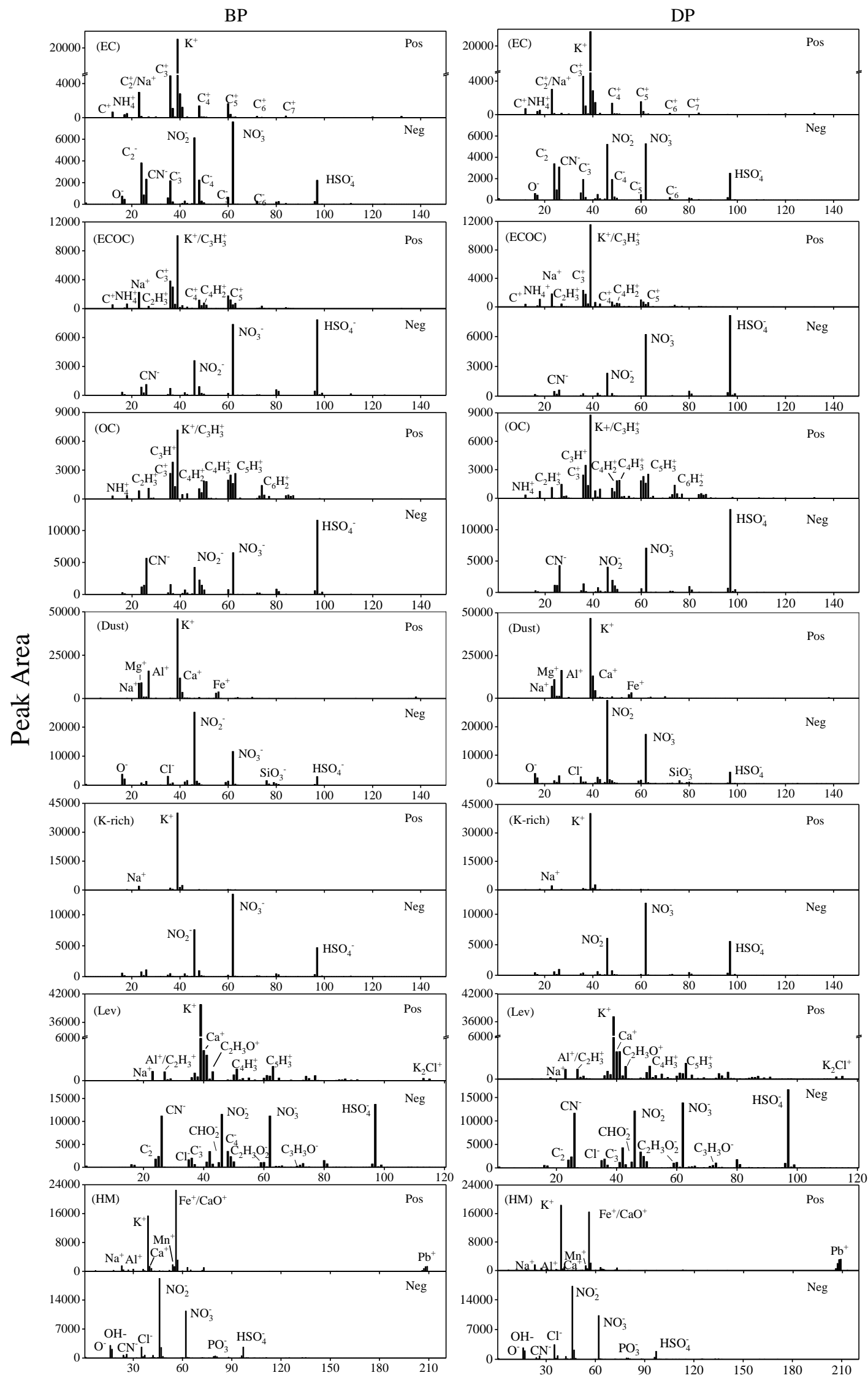

$\mathrm{m} / \mathrm{z}$

Fig. 2. Mean mass spectra of eight particle types during BP and DP. 

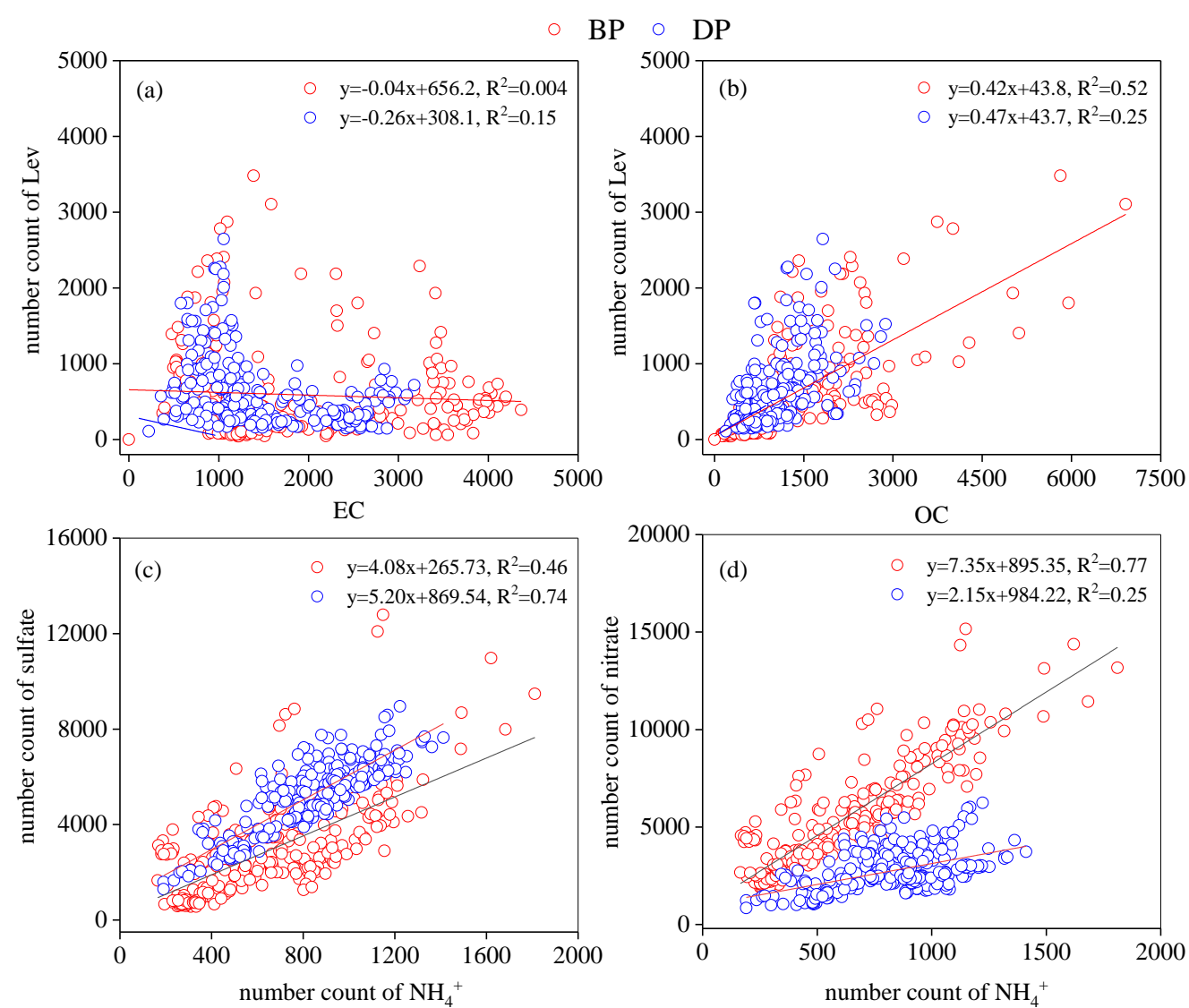

Fig. 3. Linear regressions of (a) EC and (b) $\mathrm{OC}$ with levoglucosan (Lev), and (c) nitrate and (d) sulfate with $\mathrm{NH}_{4}{ }^{+}$.

(Tao et al., 2011; Liu et al., 2016; Zhang et al., 2019). As shown in Fig. 2, dust particles during DP exhibited weaker ${ }^{23} \mathrm{Na}^{+},{ }^{56} \mathrm{Fe}^{+}$, and ${ }^{79} \mathrm{PO}_{3}{ }^{-}$signals than those during $\mathrm{BP}$, suggesting that dust particles during DP were mostly derived from mineral dust rather than industrial sources.

\section{K-rich}

K-rich particles were mainly composed of ${ }^{39} \mathrm{~K}^{+},{ }^{97} \mathrm{HSO}_{4}^{-}$, ${ }^{46} \mathrm{NO}_{2}{ }^{-}$, and ${ }^{62} \mathrm{NO}_{3}{ }^{-}$as well as ${ }^{26} \mathrm{CN}^{-}$and ${ }^{42} \mathrm{CNO}^{-}$sometimes. $\mathrm{K}$ in fine particles can be proposed as a key tracer of biomass burning (Martins et al., 2018), but since SPAMS is very sensitive to alkali metal ions, levoglucosan was considered as an important tracer of biomass burning in this study (Zhang et al., 2010; Li et al., 2011). However, only a small fraction (BP: $8.6 \%$; DP: $6.7 \%$ ) of K-rich particles contained levoglucose negative ion fragments, suggesting that the impact of biomass burning on K-rich particles was small. A few studies have shown that nitrate and sulfate in China were mainly derived from the transformation of $\mathrm{SO}_{2}, \mathrm{NO}_{2}$, and the other primary gas pollutants via heterogeneous reactions (Zhu et al., 2011; He et al., 2014). The strong signals of both nitrate and sulfate were commonly observed in the negative mass spectrum, indicating that K-rich particles may experience atmospheric ageing process during long range transport. Previous studies have demonstrated that the higher $\mathrm{RH}$ and lower temperature conditions are favorable for the formation of nitrate (Wang et al., 2016b). Therefore, the formation of nitrate was restrained under the low RH and high temperature conditions, along with the lower concentration of $\mathrm{NO}_{\mathrm{x}}$ in DP compared to those in BP. These phenomena may lead to the weaker signal of nitrate of K-rich particles obtained during DP.

\section{Levoglucosan Particles}

A total of 155962 levoglucosan particles were determined during DP, which was 1.1 times higher than that during BP, suggesting that biomass burning activities were enhanced during DP. Levoglucosan particles contained significant signals of $\mathrm{K}^{+}$, secondary inorganic ions, and levoglucose ion fragments (e.g., ${ }^{45} \mathrm{CHO}_{2}^{-},{ }^{59} \mathrm{C}_{2} \mathrm{H}_{3} \mathrm{O}_{2}^{-}$, and ${ }^{73} \mathrm{C}_{3} \mathrm{H}_{5} \mathrm{O}_{2}^{-}$). Previous studies have demonstrated that levoglucosan can decay or even disappear in particles exposed to $\cdot \mathrm{OH}$ radicals via photochemical oxidation (Hennigan et al., 2010). The negative mass spectrum exhibited the more abundant signals of nitrate and sulfate during DP compared to those during BP, largely attributed to the enhancement of photochemical oxidation during DP.

\section{Heavy Metal (HM) Particles}

A total of 103034 metal particles were determined, accounted for only $3.8 \%$ of total classified particles. The number counts of $\mathrm{HM}$ particles were similar during BP to those during DP. Strong signals of ${ }^{56} \mathrm{Fe}^{+}$and ${ }^{39} \mathrm{~K}^{+}$were observed in the positive mass spectrum during BP. Significant signal intensities of nitrated and sulfate were obtained in the negative mass spectrum during $\mathrm{BP}$, which may reflect the 
presence of aged particles. In addition, the relatively obvious signals of ${ }^{206,207,208} \mathrm{~Pb}^{+}$and ${ }^{79} \mathrm{PO}_{3}{ }^{-}$in the mass spectrum of $\mathrm{HM}$ particles during $\mathrm{BP}$, indicating that the steel manufacture and fossil fuel combustion were the important contributors to the HM particles. HM particles contained the more abundant signals of ${ }^{206,207,208} \mathrm{~Pb}^{+}$, but less signals of ${ }^{40} \mathrm{Ca}^{+}$, ${ }^{55} \mathrm{Mn}^{+},{ }^{56} \mathrm{Fe}^{+}$and sulfate during DP than those during BP.

\section{Comparison of Size Distribution between BP and DP}

The number fraction and size distribution in the range of 0.2 to $2.0 \mu \mathrm{m}$ of the eight groups of particles were presented in Figs. 4 and 5 during the whole period. As shown in Fig. 4, the unscaled size distribution of total particles exhibited a dominant peak at approximately $0.5 \mu \mathrm{m}$ during BP, and the unscaled size distribution exhibited a multi-mode distribution with peaks at the size range of $0.66-0.70 \mu \mathrm{m}$ during DP, suggesting that the size distribution during DP shifted to a coarser mode. This phenomenon was primarily attributed to the higher fraction of secondary inorganic ions via enhanced heterogeneous aqueous oxidation and to the increased hygroscopic growth of finer particles (Yang et al., 2012). Therefore, the particles can be defined as be young and aged during BP and DP, respectively. EC particles were prominent species during both BP and DP. EC particles ranged from 0.2 to $0.4 \mu \mathrm{m}$, which are mostly derived from vehicle exhausts (Liu and Shao, 2007). The number counts of EC particles in such size range were 4300 during DP, which were only one half of those during BP. The number fraction of total particles at the size of $<0.4 \mu \mathrm{m}$ decreased at different levels during DP, indicating that the reduction in concentrations of pollutants during DP can greatly alter the chemical compositions of single particles. EC can be regarded as a key tracer of primary sources (Moffet et al., 2008), the number fraction of EC particles ranging from 0.4 to $2.0 \mu \mathrm{m}$ and deceased from $33.1 \%$ during BP to $27.0 \%$ during DP due to the reduction of primary pollutants such as coal combustions and vehicle exhaust. As shown in Fig. 5, the unscaled size distribution of EC particles peaked at $0.66 \mu \mathrm{m}$ during BP, and those peaked at a larger size (about $0.7 \mu \mathrm{m}$ ) during DP are resulted from the enhanced atmospheric oxidation as discussed above. Similar to EC, the unscaled size distribution of OC particles has a peak at $0.48 \mu \mathrm{m}$ during BP and at $0.5 \mu \mathrm{m}$ during DP, largely because more abundant ${ }^{97} \mathrm{HSO}_{4}^{-}$was accumulated on the surfaces of OC particles.

Ma et al. (2016b) have reported that $\mathrm{K}^{+}$was primarily enriched in fine mode and accumulated in larger size over time. The unscaled size distribution of K-rich particles has a peak at $0.52 \mu \mathrm{m}$ during $\mathrm{BP}$ and at $0.68 \mu \mathrm{m}$ during $\mathrm{DP}$, indicating that K-rich particles remained for a long time in the atmosphere and went through a strong aging process during DP. A general increase in the number fraction of both dust particles and HM particles was found with the increase of particle size, thus both two kinds of particles were mainly distributed in the coarse mode $(>0.84 \mu \mathrm{m})$. Moreover, both dust particles and HM particles displayed the same size distributions during the whole observation period, suggesting that both particles were derived from the same sources or shared a common formation pathway during the transport. Different from other kind's particles, the size distributions of levoglucosan particles did not exhibit significant variations during BP and DP and peaked at approximately $0.5 \mu \mathrm{m}$. In addition, the number fraction of levoglucosan particles slightly decreased as the size distributions increased. This relationship was also observed in the single particles of Shanghai, China (Tao et al., 2011).

\section{Different Characteristics of Mixing State between BP and DP}

Secondary inorganic species including sulfate, nitrate, and ammonium were normally observed in different kinds of single particles and with different intensities during different pollution periods (Cahill et al., 2012; Zhang et al., 2013). The mixing state of secondary inorganic ions with the original particles can provide important information about chemical processes in the atmosphere (Liu et al., 2016). To better understand the difference of mixing state between BP and DP, ${ }^{35} \mathrm{Cl}^{-}$was also selected to present their association with each kind of particles. Almost all particles were

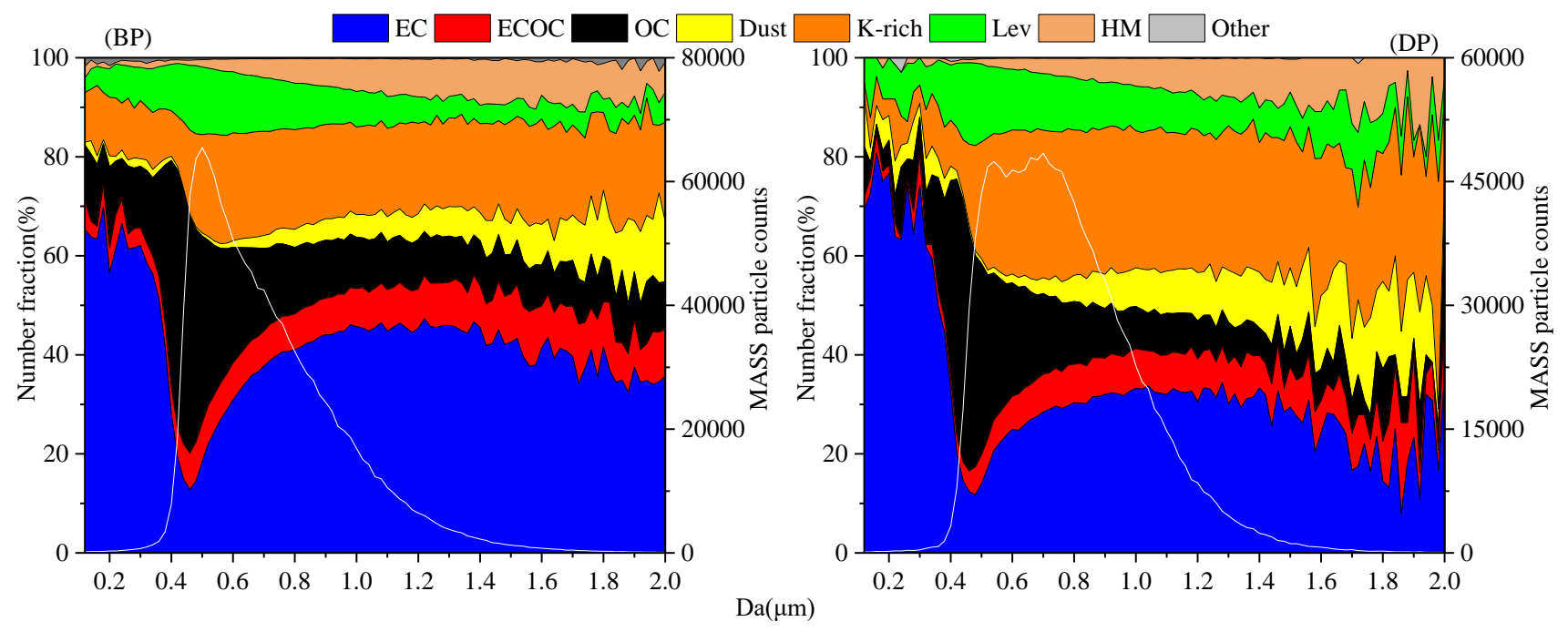

Fig. 4. Unscaled size resolved number fraction of major particle types during BP and DP. 


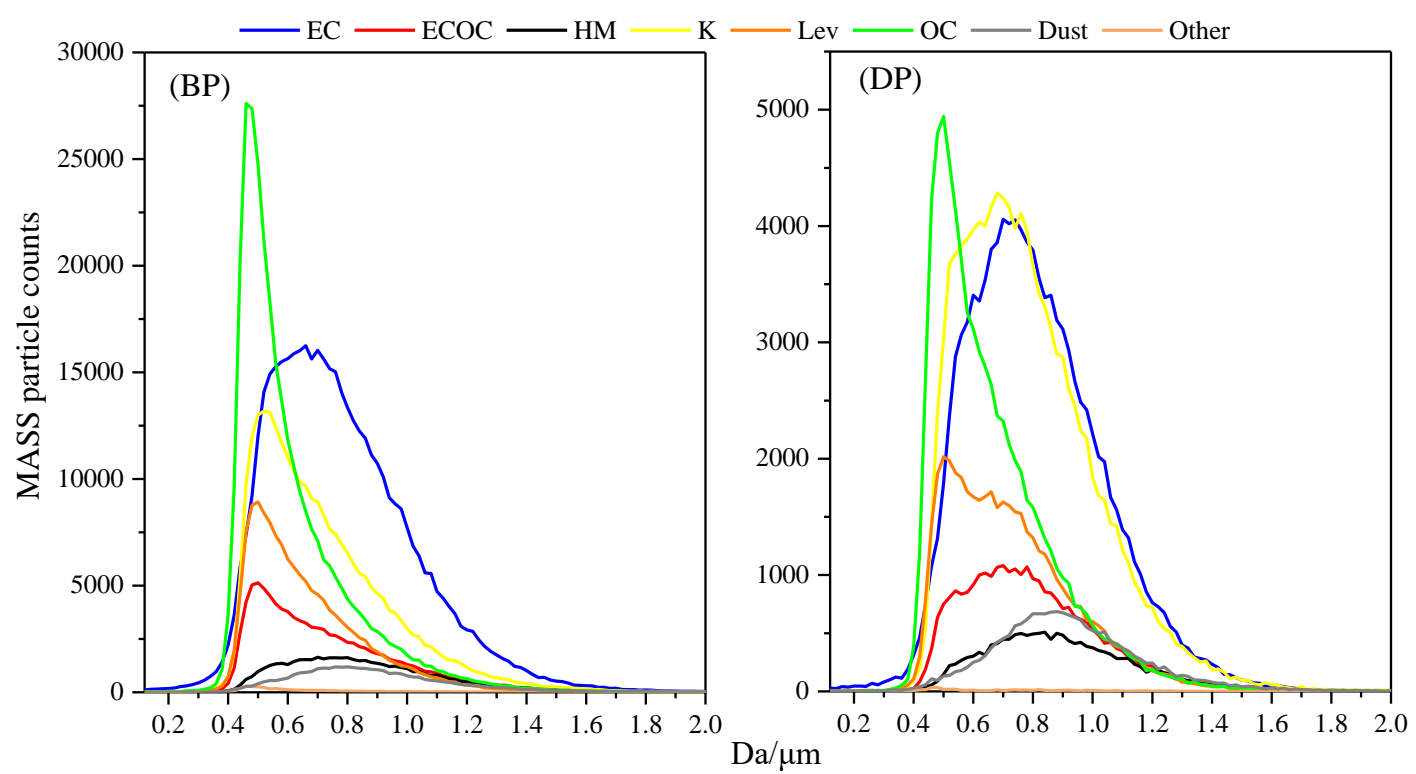

Fig. 5. Unscaled each particle size distributions during BP and DP.

enriched with more sulfate than nitrate during the whole observation period, mainly due to the higher concentration of $\mathrm{SO}_{2}$ than $\mathrm{NO}_{\mathrm{x}}$ (Table 1) as well as the different formation mechanisms of these two species. As shown in Fig. 6, more abundant nitrate was found during BP than that during DP, probably due to the relatively low relative humidity during DP. The reduction of nitrate during DP was also attributed to the decrease of $\mathrm{NO}_{\mathrm{x}}$ concentration $\left(\mathrm{BP}: 40.0 \pm 18.3 \mu \mathrm{g} \mathrm{m}^{-3}\right.$; DP: $19.5 \pm 6.3 \mu \mathrm{g} \mathrm{m}^{-3}$ ) emitted from local industry and transportation activities when industrial facilities were closed and automotive vehicles were off the road. The smaller amount of nitrate in carbonaceous particles were observed than alkaline particles during both BP and DP, because the good affinity of alkaline particles such as K-rich and HM particles to acidic gas, which makes the neutralization reaction between particles and acidic gas continuously occur, further promoting more $\mathrm{NO}_{\mathrm{x}}$ attached to the surface of particles (Bi et al., 2011). It is noteworthy that the number count of sulfate increased from 658940 during BP to 663881 during DP, largely because the stronger solar radiation and higher $\mathrm{O}_{3}$ concentration during DP favored the formation of sulfate through heterogeneous oxidation reactions (Zhang et al., 2013), despite of the similar concentration level of $\mathrm{SO}_{2}$ (Table 1 and Fig. 1).

The number of ammonium increased from 499,858 during BP to 661,463 during DP. It has been reported that ammonium in the fine mode is primarily in the form of ammonium sulfate, ammonium bisulfate, and ammonium nitrate. Ammonium nitrate is a thermally unstable species and thus low temperature can facilitate ammonium nitrate enriching in the particles (Bian et al., 2014). As shown in Fig. 3, ammonium was correlated robustly with nitrate but correlated weakly with sulfate during BP, and ammonium was correlated positively with sulfate but correlated weakly with nitrate during DP. Moreover, ammonium particles were characterized by more intensive nitrate signals than sulfate signals during BP and they were characterized by more intensive sulfate signals than nitrate signals during DP. Therefore, ammonium was mainly in the form of ammonium nitrate in BP and it was in the form of ammonium sulfate in DP, because the higher temperature during DP promoted the volatilization of ammonium nitrate. ${ }^{35} \mathrm{Cl}^{-}$is ubiquitous in the atmosphere, and it is emitted from various sources such as biomass burning, sea salt, industrial processes, and mineral dust (Yan et al., 2018; Wang et al., 2019). Liaocheng is an inland city, thus ${ }^{35} \mathrm{Cl}^{-}$was less affected by sea salt. Moreover, no correlation $\left(\mathrm{R}^{2}<0.3\right.$, Fig. 7) between ${ }^{35} \mathrm{Cl}^{-}$and dust particles was observed during both BP and DP, indicating that ${ }^{35} \mathrm{Cl}^{-}$ in the particles of Liaocheng was mainly originated from biomass burning and industrial processes. As discussed above, the enhancement of biomass burning was observed during DP, thus the decreased ${ }^{35} \mathrm{Cl}^{-}$was due to the significant reduction of industrial emissions during DP rather than biomass burning. As shown in Fig. 6, the enhanced fractions of ${ }^{35} \mathrm{Cl}^{-}$were observed in inorganic particles including dust, K-rich, levoglucosan, and HM particles during DP compared to those during BP, but the smaller amount of ${ }^{35} \mathrm{Cl}^{-}$was found in carbonaceous particles during DP than that during BP.

\section{CONCLUSIONS}

To understand the impact of the COVID-19 pandemic on the characteristics of ambient single particles in the city of Liaocheng, two typical sampling periods (i.e., before and during the pandemic) were compared to investigate the differences in chemical composition, size distribution, and mixing state of single particles. A total of 1373953 particles and 1361662 particles were obtained with both positive and negative mass spectrum during BP and DP, respectively. Single particles were classified into eight categories, including EC, ECOC, OC, Dust, K-rich, levoglucosan, HM, and other.

The concentrations of $\mathrm{PM}_{2.5}, \mathrm{NO}_{\mathrm{x}}$ and $\mathrm{CO}$ exhibited a significant decreasing trend from BP to DP due to the lockdown of the city, suspension of factory production and 

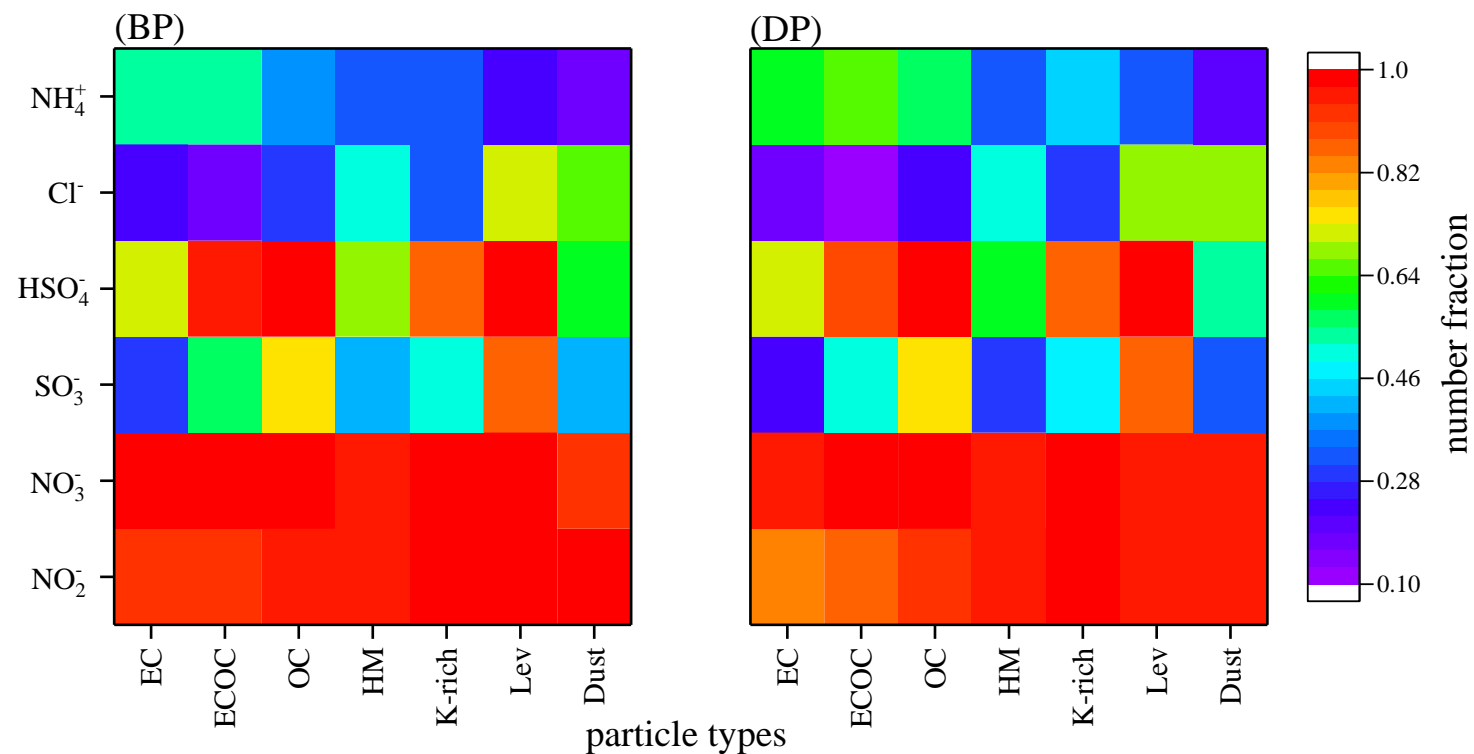

Fig. 6. Number fraction of selected markers associated with particle types.

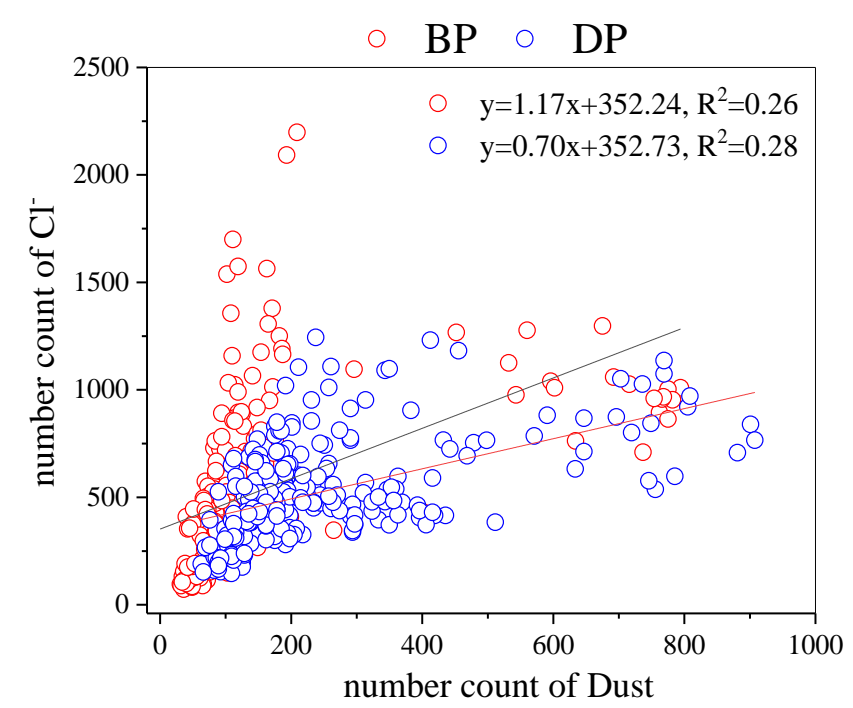

Fig. 7. Linear regression of $\mathrm{Cl}^{-}$-containing particles on dust particles.

traffic restrictions during DP. The significant signal intensities of secondary inorganic ions such as ${ }^{46} \mathrm{NO}_{2}^{-},{ }^{62} \mathrm{NO}_{3}^{-}$, and ${ }^{97} \mathrm{HSO}_{4}^{-}$in the negative mass spectrum of each classified particles were observed during the whole observation period, suggesting that particles experienced aging process in the atmosphere. The dust, levoglucosan, and HM particles during DP showed a more significant peak of secondary inorganic ions than that during $\mathrm{BP}$, indicating that the particles during DP were more aged. Compared to the size distribution during $\mathrm{BP}$, the unscaled size distribution during DP shifted to a coarser mode, largely due to the higher fraction of secondary inorganic ions via enhanced heterogeneous aqueous oxidation and the increased hygroscopic growth of finer particles. More abundant nitrate was found during BP than that during $\mathrm{DP}$, probably due to the lower $\mathrm{NO}_{\mathrm{x}}$ concentration and lower relative humidity during DP. In addition, ammonium was mainly in the form of ammonium nitrate in $\mathrm{BP}$ and it was in the form of ammonium sulfate in DP, because the higher temperature during DP promoted the volatilization of ammonium nitrate. The decreased ${ }^{35} \mathrm{Cl}^{-}$particles during DP were due to the significant reduction of industrial processes emissions during DP rather than biomass burning.

\section{ACKNOWLEDGMENTS}

This work was supported by the National Key Research and Development Program (Grant No. 2017YFC0212406 and 2016YFC0207505), National Science Foundation of China (Grant No. 41505112 and 41702373) and Natural Science Foundation of Shandong Province. (Grant No. BS2015HZ002).

\section{REFERENCES}

An, Z., Huang, R.J., Zhang, R., Tie, X., Li, G., Cao, J., Zhou, W., Shi, Z., Han, Y., Gu, Z. and Ji, Y. (2019). Severe haze in northern China: A synergy of anthropogenic emissions and atmospheric processes. Proc. Natl. Acad. Sci. U.S.A. 116: 8657-8666. https://doi.org/10.1073/pnas.1900125116

Bi, X., Zhang, G., Li, L., Wang, X., Li, M., Sheng, G., Fu, J. and Zhou, Z. (2011). Mixing state of biomass burning particles by single particle aerosol mass spectrometer in the urban area of PRD, China. Atmos. Environ. 45: $3447-$ 3453. https://doi.org/10.1016/j.atmosenv.2011.03.034

Bian, Q., Huang, X.H.H. and Yu, J.Z. (2014). One-year observations of size distribution characteristics of major aerosol constituents at a coastal receptor site in Hong Kong- Part 1: Inorganic ions and oxalate. Atmos. Chem. Phys. 14: 9013-9027. https://doi.org/10.5194/acp-149013-2014

Cahill, J.F., Suski, K., Seinfeld, J.H., Zaveri, R.A. and Prather, K.A. (2012). The mixing state of carbonaceous aerosol particles in northern and southern California 
measured during CARES and CalNex 2010. Atmos. Chem. Phys. 12: 10989-11002. https://doi.org/10.5194/acp-1210989-2012

Cheng, C., Li, M., Chan, C.K., Tong, H., Chen, C., Chen, D., Wu, D., Li, L., Wu, C., Cheng, P., Gao, W., Huang, Z., Li, X., Zhang, Z., Fu, Z., Bi, Y. and Zhou, Z. (2017). Mixing state of oxalic acid containing particles in the rural area of Pearl River Delta, China: Implications for the formation mechanism of oxalic acid. Atmos. Chem. Phys. 17: 9519-9533. https://doi.org/10.5194/acp-17-9519-2017

He, H., Wang, Y., Ma, Q., Ma, J., Chu, B., Ji, D., Tang, G., Liu, C., Zhang, H. and Hao, J. (2014). Mineral dust and $\mathrm{NO}_{\mathrm{x}}$ promote the conversion of $\mathrm{SO}_{2}$ to sulfate in heavy pollution days. Sci. Rep. 4: 4172. https://doi.org/10.1038/ srep04172

Hennigan, C.J., Sullivan, A.P., Collett, J.L. and Robinson, A.L. (2010). Levoglucosan stability in biomass burning particles exposed to hydroxyl radicals. Geophys. Res. Lett. 37: L09806. https://doi.org/10.1029/2010GL043088

Hu, B., Xu, H., Deng, J., Yi, Z., Chen, J., Xu, L., Hong, Z., Chen, X. and Hong, Y. (2018). Characteristics and source apportionment of volatile organic compounds for different functional zones in a coastal city of southeast China. Aerosol Air Qual. Res. 18: 2840-2852. https://doi.org/10. 4209/aaqr.2018.04.0122

Jain, C.D., Gadhavi, H.S., Wankhede, T., Kallelapu, K., Sudhesh, S., Das, L.N., Pai, R.U. and Jayaraman, A. (2018). Spectral properties of black carbon produced during biomass burning. Aerosol Air Qual. Res. 18: 671679. https://doi.org/10.4209/aaqr.2017.03.0102

Jiang, F., Liu, F., Lin, Q., Fu, Y., Yang, Y., Peng, L., Lian, X., Zhang, G., Bi, X., Wang, X. and Sheng, G. (2019). Characteristics and formation mechanisms of sulfate and nitrate in size-segregated atmospheric particles from urban Guangzhou, China. Aerosol Air Qual. Res. 19: 1284-1293. https://doi.org/10.4209/aaqr.2018.07.0251

Jin, X., Xu, K., Jiang, P., Lian, J., Hao, S., Yao, H., Jia, H., Zhang, Y., Zheng, L., Zheng, N., Chen, D., Yao, J., Hu, J., Gao, J., Wen, L., Shen, J., Ren, Y., Yu, G., Wang, X., ... Yang, Y. (2020). Virus strain from a mild COVID19 patient in Hangzhou represents a new trend in SARSCoV-2 evolution potentially related to Furin cleavage site. Emerging Microbes Infect. 9: 1474-1488. https://doi. org/10.1080/22221751.2020.1781551

Le, T., Wang, Y., Liu, L., Yang, J., Yung, Y.L., Li, G. and Seinfeld, J.H. (2020). Unexpected air pollution with marked emission reductions during the COVID-19 outbreak in China. Science 2020: eabb7431. https://doi.org/10.1126/s cience.abb7431

Li, J., Wang, G., Zhang, Q., Li, J., Wu, C., Jiang, W., Zhu, T. and Zeng, L. (2019). Molecular characteristics and diurnal variations of organic aerosols at a rural site in the North China Plain with implications for the influence of regional biomass burning. Atmos. Chem. Phys. 19: 10481-10496. https://doi.org/10.5194/acp-19-10481-2019

Li, L., Huang, Z., Dong, J., Li, M., Gao, W., Nian, H., Fu, Z., Zhang, G., Bi, X., Cheng, P. and Zhou, Z. (2011). Real time bipolar time-of-flight mass spectrometer for analyzing single aerosol particles. Int. J. Mass spectrom. 303: 118-
124. https://doi.org/10.1016/j.ijms.2011.01.017

Li, L., Li, M., Huang, Z., Gao, W., Nian, H., Fu, Z., Gao, J., Chai, F. and Zhou, Z. (2014). Ambient particle characterization by single particle aerosol mass spectrometry in an urban area of Beijing. Atmos. Environ. 94: 323-331. https://doi.org/10.1016/j.atmosenv.2014.03.048

Liu, L., Wang, Y., Du, S., Zhang, W., Hou, L., Vedal, S., Han, B., Yang, W., Chen, M. and Bai, Z. (2016). Characteristics of atmospheric single particles during haze periods in a typical urban area of Beijing: A case study in October, 2014. J. Environ. Sci. 40: 145-153. https://doi.org/10.1016/j.jes.2015.10.027

Liu, X., Meng, J., Hou, Z., Yan, L., Wang, G., Yi, Y., Wei, B., Fu, M., Li, J. and Cao, J. (2019). Molecular compositions and sources of organic aerosols from urban atmosphere in the North China Plain during the wintertime of 2017. Aerosol Air Qual. Res. 19: 22672280. ttps://doi.org/10.4209/aaqr.2019.08.0418

Liu, Y. and Shao, M. (2007). Estimation and prediction of black carbon emissions in Beijing city. Chin. Sci. Bull. 52: 1274-1281. https://doi.org/10.1007/s11434-007-0162-8

Lu, J., Ma, L., Cheng, C., Pei, C., Chan, C.K., Bi, X., Qin, Y., Tan, H., Zhou, J., Chen, M., Li, L., Huang, B., Li, M. and Zhou, Z. (2019). Real time analysis of leadcontaining atmospheric particles in Guangzhou during wintertime using single particle aerosol mass spectrometry. Ecotoxicol. Environ. Saf. 168: 53-63. https://doi.org/10.1 016/j.ecoenv.2018.10.006

Ma, L., Li, M., Huang, Z., Li, L., Gao, W., Nian, H., Zou, L., Fu, Z., Gao, J., Chai, F. and Zhou, Z. (2016a). Real time analysis of lead-containing atmospheric particles in Beijing during springtime by single particle aerosol mass spectrometry. Chemosphere 154: 454-462. https://doi.org/ 10.1016/j.chemosphere.2016.04.001

Ma, L., Li, M., Zhang, H., Li, L., Huang, Z., Gao, W., Chen, D., Fu, Z., Nian, H., Zou, L., Gao, J., Chai, F. and Zhou, Z. (2016b). Comparative analysis of chemical composition and sources of aerosol particles in urban Beijing during clear, hazy, and dusty days using single particle aerosol mass spectrometry. J. Cleaner Prod. 112: 1319-1329. https://doi.org/10.1016/j.jclepro.2015.04.054

Martins, L.D., Hallak, R., Alves, R.C., de Almeida, D.S., Squizzato, R., Moreira, C.A.B., Beal, A., da Silva, I., Rudke, A. and Martins, J.A. (2018). Long-range transport of aerosols from biomass burning over Southeastern South America and their implications on air quality. Aerosol Air Qual. Res. 18: 1734-1745. https://doi.org/10. 4209/aaqr.2017.11.0545

Meng, J., Liu, X., Hou, Z., Yi, Y., Yan, L., Li, Z., Cao, J., Li, J. and Wang, G. (2020). Molecular characteristics and stable carbon isotope compositions of dicarboxylic acids and related compounds in the urban atmosphere of the North China Plain: Implications for aqueous phase formation of SOA during the haze periods. Sci. Total Environ. 705: 135256. https://doi.org/10.1016/j.scitotenv. 2019.135256

Mochida, M., Kawamura, K., Fu, P. and Takemura, T. (2010). Seasonal variation of levoglucosan in aerosols over the western North Pacific and its assessment as a 
biomass-burning tracer. Atmos. Environ. 44: 3511-3518. https://doi.org/10.1016/j.atmosenv.2010.06.017

Moffet, R.C., de Foy, B., Molina, L.T., Molina, M.J. and Prather, K.A. (2008). Measurement of ambient aerosols in northern Mexico city by single particle mass spectrometry. Atmos. Chem. Phys. 8: 4499-4516. https://doi.org/10.5194/acp-8-4499-2008

Simoneit, B.R.T., Elias, V.O., Kobayashi, M., Kawamura, K., Rushdi, A.I., Medeiros, P.M., Rogge, W.F. and Didyk, B.M. (2004). Sugarsdominant water-soluble organic compounds in soils and characterization as tracers in atmospheric particulate matter. Environ. Sci. Technol. 38: 5939-5949. https://doi.org/10.1021/es0403099

Sun, Y.L., Wang, Z.F., Fu, P.Q., Yang, T., Jiang, Q., Dong, H.B., Li, J. and Jia, J.J. (2013). Aerosol composition, sources and processes during wintertime in Beijing, China. Atmos. Chem. Phys. 13: 4577-4592. https://doi.org/ 10.5194/acp-13-4577-2013

Tao, S., Wang, X., Chen, H., Yang, X., Li, M., Li, L. and Zhou, Z. (2011). Single particle analysis of ambient aerosols in Shanghai during the World Exposition, 2010: Two case studies. Front. Environ. Sci. Eng. China 5: 391401. https://doi.org/10.1007/s11783-011-0355-X

Tian, H., Liu, Y., Li, Y., Wu, C.H., Chen, B., Kraemer, M.U.G., Li, B., Cai, J., Xu, B., Yang, Q., Wang, B., Yang, P., Cui, Y., Song, Y., Zheng, P., Wang, Q., Bjornstad, O.N., Yang, R., Grenfell, B.T., ... Dye, C. (2020). An investigation of transmission control measures during the first 50 days of the COVID-19 epidemic in China. Science 368: 638. https://doi.org/10.1126/science.abb6105

Tobías, A., Carnerero, C., Reche, C., Massagué, J., Via, M., Minguillón, M.C., Alastuey, A. and Querol, X. (2020). Changes in air quality during the lockdown in Barcelona (Spain) one month into the SARS-CoV-2 epidemic. Sci. Total Environ. 726: 138540. https://doi.org/10.1016/j.scit otenv.2020.138540

Wang, C., Horby, P.W., Hayden, F.G. and Gao, G.F. (2020). A novel coronavirus outbreak of global health concern. Lancet. 395: 470-473. https://doi.org/10.1016/S01406736(20)30185-9

Wang, G., Zhang, R., Gomez, M.E., Yang, L., Levy Zamora, M., Hu, M., Lin, Y., Peng, J., Guo, S., Meng, J., Li, J., Cheng, C., Hu, T., Ren, Y., Wang, Y., Gao, J., Cao, J., An, Z., Zhou, W., ... Molina, M.J. (2016a). Persistent sulfate formation from London Fog to Chinese haze. Proc. Natl. Acad. Sci. U.S.A. 113: 13630-13635. https://doi.org/10.1073/pnas.1616540113

Wang, H., An, J., Shen, L., Bin, Z., Li, X., Qing, D. and Zou, J. (2016b). Mixing state of ambient aerosols in Nanjing city by single particle mass spectrometry. Atmos. Environ. 132: 123-132. https://doi.org/10.1016/j.atmosenv.2016.02.032

Wang, S., He, B., Yuan, M., Su, F., Yin, S., Yan, Q., Jiang, N., Zhang, R. and Tang, X. (2019). Characterization of individual particles and meteorological conditions during the cold season in Zhengzhou using a single particle aerosol mass spectrometer. Atmos. Res. 219: 13-23. https://doi.org/10.1016/j.atmosres.2018.12.021
Xu, K., Cui, K., Young, L.H., Hsieh, Y.K., Wang, Y.F., Zhang, J. and Wan, S. (2020a). Impact of the COVID-19 event on air quality in central China. Aerosol Air Qual. Res. 20: 915-929. https://doi.org/10.4209/aaqr.2020.04.0150

Xu, K., Cui, K., Young, L.H., Wang, Y.F., Hsieh, Y.K., Wan, S. and Zhang, J. (2020b). Air quality index, indicatory air pollutants and impact of COVID-19 event on the air quality near central China. Aerosol Air Qual. Res. 20: 1204-1221. https://doi.org/10.4209/aaqr.2020.04.0139

Yan, J., Chen, L., Lin, Q., Zhao, S. and Li, L. (2018). Pollutants identification of ambient aerosols by two types of aerosol mass spectrometers over southeast coastal area, China. J. Environ. Sci. 64: 252-263. https://doi.org/10.10 16/j.jes.2017.06.030

Yang, F., Chen, H., Du, J., Yang, X., Gao, S., Chen, J. and Geng, F. (2012). Evolution of the mixing state of fine aerosols during haze events in Shanghai. Atmos. Res. 104-105: 193-201. https://doi.org/10.1016/j.atmosres.20 11.10.005

Zhai, J., Wang, X., Li, J., Xu, T., Chen, H., Yang, X. and Chen, J. (2015). Thermal desorption single particle mass spectrometry of ambient aerosol in Shanghai. Atmos. Environ. 123: 407-414. https://doi.org/10.1016/j.atmosen v.2015.09.001

Zhang, G., Bi, X., Li, L., Chan, L.Y., Li, M., Wang, X., Sheng, G., Fu, J. and Zhou, Z. (2013). Mixing state of individual submicron carbon-containing particles during spring and fall seasons in urban Guangzhou, China: A case study. Atmos. Chem. Phys. 13: 4723-4735. https://doi.org/10.5194/acp-13-4723-2013

Zhang, G., Han, B., Bi, X., Dai, S., Huang, W., Chen, D., Wang, X., Sheng, G., Fu, J. and Zhou, Z. (2015). Characteristics of individual particles in the atmosphere of Guangzhou by single particle mass spectrometry. Atmos. Res. 153: 286-295. https://doi.org/10.1016/j.atm osres.2014.08.016

Zhang, J., Huang, X., Chen, Y., Luo, B., Luo, J., Zhang, W., Rao, Z. and Yang, F. (2019). Characterization of leadcontaining atmospheric particles in a typical basin city of China: Seasonal variations, potential source areas, and responses to fireworks. Sci. Total Environ. 661: 354-363. https://doi.org/10.1016/j.scitotenv.2019.01.079

Zhang, Z., Engling, G., Lin, C.Y., Chou, C.C.K., Lung, S.C.C., Chang, S.Y., Fan, S., Chan, C.Y. and Zhang, Y.H. (2010). Chemical speciation, transport and contribution of biomass burning smoke to ambient aerosol in Guangzhou, a mega city of China. Atmos. Environ. 44: 3187-3195. https://doi.org/10.1016/j.atmosenv.2010.05.024

Zhu, T., Shang, J. and Zhao, D. (2011). The roles of heterogeneous chemical processes in the formation of an air pollution complex and gray haze. Sci. China Chem. 54: 145-153.https://doi.org/10.1007/s11426-010-4181-y

Received for review, June 18, 2020 Revised, July 11, 2020 Accepted, July 13, 2020 